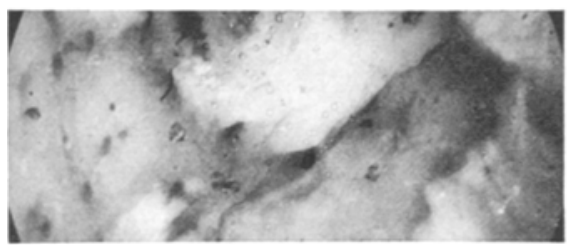

Fig. 6a. Recovering ulcerative colitis. Left colon. Mucous surface: wide depressed areas and roughness of the surface; several gland openings can be observed. $\times 50$.

the former we observed wide depressed areas and roughness of the surface, varying in size and clear-cut on the surrounding areas. At the bottom of these, the gland openings appear often altered and irregularly scattered (Figure 6a). In a case of adeno-carcinoma, the surface specimens showed a grossly alveolar picture formed by depressions and by large interconnecting folds. The depressed areas seemed to correspond to irregular and enlarged openings of the glands.

These preliminary data seem to show the suitability of the surface microscopy in the study of the colon. They provide a number of pictures which probably represent either structural or functional aspects concerned with the activity of the muscularis mucosae. It is also possible that they permit a better comparison between the histological and radiological picture ${ }^{4}$.

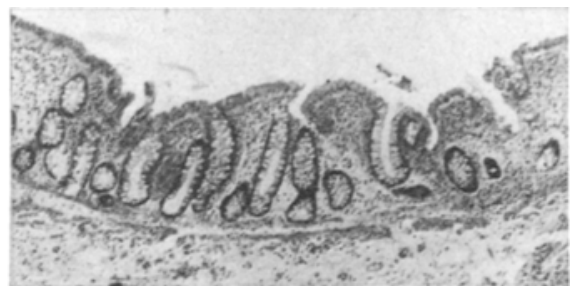

Fig. 6b. Histological pattern of the same specimen showing the wavelike aspect of the mucous surface. $\times 50$.

Riassunto. La microscopia di superficie costituisce una integrazione dell'istologia convenzionale. E possibile che essa sveli anche aspetti utili per lo studio dei momenti funzionali della mucosa.

A. Fabbrini, A. Torsoli, A. Alessandrini, L. Onori, V. Greco, C. Casale, P. Arullant, and M. RE

Istituto di Patologia Speciale Medica e Metodologia Clinica dell'Università di Roma (Italy),

August 12, 1965.

4 Aided by grants from Consiglio Nazionale delle Ricerche (CNR).

\section{Pharmacological Properties of Neurones of the Paramedian Reticular Nucleus}

The paramedian reticular nucleus (n.r.p.) has been identified by anatomical techniques as a cerebellar projecting reticular nucleus of the medulla, ${ }^{\mathbf{1 , 2}}$. In the course of experiments on cholinoceptive neurones in the cat brain stem $^{3}$ it became apparent that a group of neurones in the same region as n.r.p. were consistently excited by acetylcholine. Accordingly, experiments were made to determine responses of n.r.p. neurones to iontophoretically applied drugs.

Cats were decerebrated under halothane anaesthesia and the cerebellum was removed to expose the floor of the IVth ventricle. Bipolar stimulating electrodes were inserted into one cerebellar peduncle and four- or fivebarrelled glass micropipettes were inserted through the floor of the IVth ventricle. Recordings were made from single neurones and drugs were expelled with currents of 50-100 nA.

When penetrations were made between 1.0 and $3.5 \mathrm{~mm}$ rostral to the obex and between 0.4 and $1.2 \mathrm{~mm}$ lateral to the mid-line, many neurones were found which gave an antidromic response to stimulation of the ipsilateral cerebellar peduncle, the latency on most occasions being between 0.6 and $1.6 \mathrm{msec}$. These neurones were presumed to belong to n.r.p.

The effect of drugs on the spontaneous activity of these neurones was examined. Acetylcholine was applied to 42 and of these it excited 39 and left 3 unaffected; this response could be blocked by application of gallamine from another barrel of the micropipette. Noradrenalin was applied to 19 of which it inhibited 17,2 being unaffected, and 5-hydroxytryptamine, applied to 20 excited 16 , inhibited 1 and left 3 unaffected. Thus, with a few exceptions these neurones are of one pharmacological type, being excited by acetylcholine, inhibited by noradrenalin and excited by 5-hydroxytryptamine. In this respect they differ from a random sample of brain stem neurones since these show a wide variety in their responses to acetylcholine, noradrenalin and $5-\mathrm{H}^{4}{ }^{4}$.

Thus, from these results it appears that uniformity of function may be associated with some degree of uniformity of pharmacological properties in brain stem neurones.

Zusammenfassung. Die chemische Sensitivität von Neuronen des Nucleus reticularis paramedianus mit cerebellärer Projektion wurde iontophoretisch untersucht. Die Mehrzahl der Neurone werden erregt durch Acetylcholin und 5-HT, dagegen gehemmt durch Noradrenalin.

G. L. Avanzino, P. B. Bradley, and J. H. Wolstencroft

Medical Research Council Neuropharmacology Research Unit, Medical School, Birmingham 15 (England), January 10, 1966.

1 A. Brodal, J. comp. Neurol. 98, 113 (1953).

2 A. Brodal and A. Torvik, J. Neurophysiol. 17, 484 (1954).

3 P. B. Bradiey, B. N. Dhawan, and J. H. Wolstencroft, J. Physiol., in press.

4 P. B. Bradley and J. H. Wolstencroft, Br. Med. Bull. 21, 15 (1965). 